\title{
Third-Party Policing Approaches against Organized Crime: an Evaluation of the Yakuza Exclusion Ordinances*
}

\author{
Tetsuya Hoshino ${ }^{\dagger} \quad$ Takuma Kamada ${ }^{\ddagger}$ \\ Published in Journal of Quantitative Criminology ${ }^{\S}$ \\ Abstract
}

Objective: Third-party policing (TPP) refers to police efforts to persuade or coerce third parties to take some responsibility for crime control and prevention. The Yakuza Exclusion Ordinances (YEOs) of Japan aim to combat organized crime syndicatesthe yakuza. Consistent with the principles of TPP, the YEOs prohibit third parties (i.e., non-yakuza individuals) from providing any benefit to the yakuza. We argue that the effectiveness of the YEOs may depend on the strategic relationship among yakuza syndicates, where yakuza syndicates choose their power strategically to gain advantages over competition among rival yakuza syndicates.

Methods: We use unique data on the yakuza and construct a regional concentration index of yakuza syndicates. Exploiting prefecture-level variation in the YEOs' enactment dates, we apply a difference-in-differences approach, while allowing for heterogeneity of the YEOs' effect by the concentration of yakuza syndicates.

Results: The YEOs decrease the number of yakuza members and the effect of YEOs is greater in regions with lower concentration levels of yakuza syndicates. Given that yakuza members decrease by about $30 \%$ during the period of our study, our estimates suggest that the YEOs on average contribute to about $20 \%$ of a recent reduction of yakuza members.

Conclusions: The YEOs are related to TPP strategies that rely on coercive techniques, and thus our results suggest the effectiveness of TPP strategies against organized crime. Furthermore, the heterogeneity of the YEOs' effect suggests the effectiveness of enforcement policies that intensively target regions with lower concentration of organized crime.

Keywords: Third-party policing, organized crime, illegal markets, quasi-experiment

*Names in alphabetical order; we contributed equally to this study. We thank Daniel DellaPosta, Corina Graif, Noboru Hirosue, Hajime Katayama, Hanae Katayama, Yoshiki Kobayashi, Thomas A. Lougrhran, Yutaka Maeda, Mark Moore, Jun Nakabayashi, Kentaro Nakajima, Holly Nguyen, Wayne Osgood, Brian Phillips, Barry Ruback, Peter Reuter, Tomoyori Saito, Yoshimichi Sato, Stephanie M. Scott, Nobuo Suzuki, Christopher Winship, Letian Zhang, and the participants at the 38th Annual APPAM Fall Research Conference, Osaka University, Pennsylvania State University, and Tohoku University for their helpful comments and discussion. We also thank the editor and three anonymous referees for their comments. Kamada would like to thank Grant-in-Aid from the Japan Society for the Promotion of Science Fellows (26-5010). The usual disclaimer applies.

${ }^{\dagger}$ Department of Economics, ITAM. Email: tetsuya.hoshino@itam.mx

${ }^{\ddagger}$ Corresponding author. Osaka School of International Public Policy, Osaka University. Email: kamada@osipp.osaka-u.ac.jp

$\S$ Publisher Version. 


\section{Introduction}

Crime control and prevention are central interests in the field of criminology, and many policing strategies have been proposed and implemented. Third-party policing (TPP) is an emergent policing strategy that relies on resources and institutions other than the police to address crime problems (Weisburd and Majmundar, 2018). More specifically, TPP refers to police efforts to persuade or coerce third parties - for instance, non-offending individuals who the police believe influence those participating in the target crime - to take some responsibility for crime control and prevention. TPP strategies have certain advantages over traditional policing strategies. When only the police address crime problems, their control capacity may be limited, but the TPP strategies may expand the capacity by mobilizing third parties (Mazerolle and Ransley, 2004). Previous studies have suggested the effectiveness of TPP for combating street-level crime and disorder, at least in the short term (Weisburd and Majmundar, 2018). While the principles of TPP can be directed at types of crime other than street-level crime, such as white-collar crime and terrorism (Mazerolle and Ransley, 2006), less is known about the effectiveness of TPP in combating organized crime. It is not obvious whether and, if so, how the principles of TPP operate when they are applied to organized crime. Third parties may not be willing to take responsibility for addressing organized crime in partnership with the police due to a fear of potential retaliation by members of criminal organizations.

In this paper, we take an initial step toward understanding the effect of a TPP-related strategy on organized crime. In particular, we study the effect of the Yakuza Exclusion Ordinances (YEOs). The YEOs are ordinances that were recently introduced in Japan to regulate Japanese criminal organizations: the yakuza. We use "yakuza" as a general term referring to Japanese criminal organizations or their members. The yakuza have many legal and illegal income sources, including extortion, protection rackets, interference in civil disputes, and the construction of public works. Therefore, the yakuza's economic activities are based on relationships with non-yakuza individuals and companies (henceforth, nonyakuza). The YEOs aim to sever the economic association between the yakuza and nonyakuza, thereby indirectly weakening the yakuza's economy (which is expected to aid nonyazuka in maintaining peace within their communities, as well as developing their business activities). Specifically, the YEOs prohibit non-yakuza from acting in ways that may benefit the yakuza. For example, non-yakuza are banned from receiving extra-state protection from yakuza members, renting apartments to them, and opening bank accounts for them. The YEOs are expected to increase the cost of belonging to the yakuza. To involve non-yakuza in the control of yakuza, the YEOs impose sanctions on non-yakuza if they do not abide by 
the regulations.

We propose that the YEOs can be interpreted as a TPP-related strategy. The concept underlying the YEOs can be described as "yakuza versus the police in partnership with nonyakuza." That is, the YEOs attempt to address the yakuza in partnership with non-yakuzai.e., third parties - who could aid yakuza in their activities through the aforementioned types of economic association. Thus, the YEOs can be situated as a TPP-related strategy that targets specific offenders (yakuza members) in partnership with third parties (non-yakuza). The partnership is built on the aforementioned coercive techniques. The YEOs alter the routine behaviors of non-yakuza to help them control the yakuza and reduce underlying criminal opportunity structures that allow yakuza activities to persist. We revisit this point in Section 2, elaborating on how the YEOs are, at least conceptually, related to TPP.

While the YEOs impose sanctions on non-yakuza to combat the yakuza, we argue that the effectiveness of the YEOs may depend on regional conflict and competition among rival yakuza syndicates. The intuition behind this idea is "strategic relationship" among yakuza syndicates. Crime syndicates can be considered to be rational and strategic agents in the sense that when they make a decision, they take into account how rival crime syndicates will respond (e.g., Dell, 2015). Therefore, whether yakuza members defect from their syndicates potentially depends not only on the YEOs, but also on the extent of potential regional conflict and competition with their rival syndicates.

To estimate the YEOs' effect, we take a difference-in-differences (DiD) approach, exploiting variation in the enactment dates of the YEOs across prefectures. To account for the regional competition among rival yakuza syndicates, we construct a regional concentration index of yakuza syndicates, which we call a yakuza concentration index (YCI). Using this design, we examine (i) the YEOs' effect on the number of yakuza members and (ii) the heterogeneity of the YEOs' effect by YCI.

Our study is important and unique for several reasons. First, unlike many other countries, Japan does not prohibit citizens from organizing or joining the yakuza, upholding the Freedom of Association article (Article 21) of the Japanese constitution. This feature allows us to obtain unique data on the number of yakuza members. Second, while quantitative analyses of organized crime tend to focus on violence as a means of understanding shifts in the activity of criminal organizations, especially in the context of drug-related crime (e.g., Dell, 2015), we examine the size of organized crime, that is, the number of yakuza members. Third, there has been a little investigation into the effect of TPP strategies on organized crime; rather, research has primarily focused on how agencies maintain partnerships (e.g., Ayling, 2017; Kleemans and Huisman, 2015). Examining the effect, we will provide key policy implications. 


\section{Yakuza Exclusion Ordinances}

\subsection{Background on the Yakuza}

We provide background information about the yakuza that is necessary to understand our research design. This review is not comprehensive. For a more comprehensive review, see, for example, Hill (2003, 2004).

Economic Activities of the Yakuza. There are several strands of economic activitiesboth legal and illegal - in which the yakuza engage. Among the illegal economic activities, the yakuza's main traditional income sources are as follows: extortion, the distribution of methamphetamine, gambling, and illegal bookmaking (National Police Agency, 2009). However, the yakuza's economic activities - both legal and illegal income sources - vary according to the social landscape and time period. The yakuza's contemporary economic activities, for instance, are more diverse than their past activities (National Police Agency, 2015).

Ever since the Japanese economic boom in the 1950s, the yakuza have been engaged in protection racketeering to make money illegally (mikajimeryō) from business entities such as the sex industry. They have also made money illegally from gambling and extortion. Since the economic boom, the yakuza have had an enormous influence over the Japanese infrastructure and construction sectors. The yakuza's economic activity grew in the 1970s and 1980s, and since then, the yakuza have been referred to as the economic yakuza (Hill, 2003, 2004). For instance, they have benefited from lending money at illegally high interest rates and from serving as corporate blackmailers (sōkaiya) who abuse the rights of stakeholders to extort money. They have also interfered with civil disputes (minbō). Since official legal processes are often slow and costly, some non-yakuza have chosen to have the yakuza resolve their problems (Milhaupt and West, 2000). The yakuza also targeted the construction of nuclear reactors. Nuclear reactors entail large site-specific investments, offering the yakuza a lucrative target. The level of extortion increases when a utility announces plans to build a reactor (Ramseyer, 2016). Behind all of these activities is the threat of violence.

We draw the following two conclusions from this section. First, the yakuza have a number of legal and illegal income sources. The yakuza are associated with the non-yakuza in many ways, and this association may be either voluntary or involuntary. This economic association motivates a policing strategy that attempts to keep non-yakuza away from the yakuza. Second, the yakuza's economic activities may vary with the social landscape and time period. 
Yakuza Syndicates. Despite their involvement in illegal activities, it is not illegal to organize or join yakuza syndicates in Japan. This fact creates a sharp distinction between Japan and many other countries in which it is illegal to organize or join crime syndicates. It is true that the yakuza traditionally have been socially tolerated in Japan, at least to some extent, but the recent victimization of non-yakuza by the yakuza have led the government to tighten its restrictions on the yakuza.

One of the regulations is the Anti-Yakuza Laws (Bōryokudan Taisaku Hō), enacted in 1992. Under these laws, 21 yakuza syndicates are "designated" based on a set of criteria during the period of this study. The criteria for the designation are that (i) the yakuza syndicate has a hierarchical organizational structure, (ii) its members use violence to make money, and (iii) its members have criminal records. As of 2009 (before the introduction of the YEOs), there were 82,600 yakuza members in total, and approximately $96 \%$ of them belonged to one of the designated yakuza syndicates. This percentage did not change over the period of our study (National Police Agency, 2009, 2014). Moreover, data on the yakuza syndicates are usually restricted to the designated ones. Hence, we focus on the designated yakuza syndicates and refer to them simply as yakuza. ${ }^{1}$

\subsection{Yakuza Exclusion Ordinances as Third-Party Policing}

We introduce the Yakuza Exclusion Ordinances (YEOs) and discuss the conceptual relationship between TPP strategies and the YEOs. To begin, we review TPP strategies.

Third-Party Policing. TPP attempts to control and prevent crime by mobilizing nonoffending persons, organizations, and community members whom the police identify as useful levers in controlling the target crime (Mazerolle and Ransley, 2006). There are three parties involved: the police, the target of the crime control or prevention, and an external entitynamely, a third party - with whom the police partner to address the crime. The target of TPP may be specific offenders (e.g., gang members and drug dealers), specific locations (e.g., crime hot spots), crime victims, or criminogenic situations. The key concept governing TPP is that the police address the target crime indirectly through a partnership with a third party. Another defining feature of TPP is its legal basis - which may include municipal ordinances, mandatory reporting, or conduct licensing - that shapes police efforts to incorporate third parties into the labor of crime management (Mazerolle and Ransley, 2006). In mobilizing third parties, TPP attempts to alter the third parties' routine behaviors to control the target problem or reduce underlying criminogenic conditions that cause, escalate, and sustain the

\footnotetext{
${ }^{1}$ There used to be 22 designated yakuza syndicates, but in 2011, 2 of them, both of which operated only in Okinawa, merged.
} 
problem of interest. Through the partnership, pulled by legal levers, with third parties, TPP is expected to expand the control capacity and manage the target problem (Weisburd and Majmundar, 2018).

For TPP to work effectively, partnerships with third parties are crucial. Techniques to involve third parties vary in nature from collaborative to coercive (Mazerolle et al., 2013). On the one hand, TPP can involve voluntary and cooperative partnerships between the police and third parties. In this type of partnership, the police may engage in cooperative consultation with third parties to persuade them to take responsibility for crime control and prevention. On the other hand, TPP may rely on coercive techniques. One of the fundamental challenges of TPP is to overcome third-party resistance, as not all individuals are willing to cooperate with the police (Buerger, 2014). In this case, the police may initiate actions that coerce third parties to cooperate. Such actions may include issuing citations to non-compliant individuals and initiating prosecution against violators to obtain court-forced compliance (Mazerolle and Ransley, 2004).

While existing evidence on TPP centers on street-level crimes, the principles of TPP can also be applied to terrorism, tax evasion, and white-collar crime (Mazerolle and Ransley, 2006). Approaches similar to TPP that are designed to combat organized crime recently have been applied in Europe. An example of such an approach is a multi-agency approach in which government agencies other than the police address problems in partnership with one another by sharing information across different agencies (e.g., Bjelland and Vestby, 2017; Webster, 2015); this kind of approach is also referred to the administrative approach to organized crime (e.g., Ayling, 2017; Kleemans and Huisman, 2015; Peters and Spapens, 2015). For instance, because real estate transactions could provide criminal organizations with opportunities for money laundering, commercial exploitation, and the illegal drug production, the Red Light District project aimed to regain control over the exploitation of property (Kleemans and Huisman, 2015). To this end, a multi-agency approach was taken to facilitate informationsharing and cooperation among the Red Light District team, which consists of city councilors, the public administration, police, and tax authorities.

In addition to the multi-agency approach that relies on a voluntary partnership between agencies, there are anti-association laws that prohibit non-criminal citizens from associating with members of criminal organizations. These anti-association laws are, in spirit, similar to the YEOs. Ayling (2017) discusses three types of anti-association laws in the context of Australia: control orders, consorting laws, and proscriptions on the public gathering of members of criminal organizations. For instance, seeking to make it more difficult for criminal organizations to engage in planned criminal activity and to prevent individuals from strengthening their ties with the organizations, the consorting laws make it a criminal offense 
to associate with members of declared criminal organizations. However, the effectiveness of these laws is less known.

Yakuza Exclusion Ordinances. Japan recently increased its enforcement against the yakuza by introducing the YEOs. ${ }^{2}$ The basic concept underlying the YEOs is "society versus the yakuza." This approach is a contrast to the more traditional approach based on the concept of "the police versus the yakuza." In the traditional approach, the police attempt to regulate the yakuza directly, for instance, by severely punishing yakuza members who commit crimes. In contrast, the YEOs involve non-yakuza individuals and companies in addressing the yakuza problem. We propose that the YEOs can be considered, at least conceptually, as a TPP approach. TPP involves three parties - the police, a targeted crime, and a third party. Similarly, the YEOs involve the police, the yakuza as a target, and the non-yakuza as a third party.

The YEOs are prefecture-level ordinances that are enacted by the local government of each prefecture. By prohibiting non-yakuza from providing any benefit to the yakuza, the YEOs aim to eliminate the yakuza's income flow and to weaken the yakuza, thereby helping non-yakuza to live peaceful lives as well as soundly develop their business activities. For example, the YEOs ban non-yakuza from receiving extra-state protection by yakuza members. The YEOs also prohibit non-yakuza from renting houses, apartments, or offices to yakuza members and opening bank accounts on their behalf as well as selling insurance to them. Thus, the YEOs attempt to alter the routine behaviors of non-yakuza to eliminate economic opportunities for the yakuza. As previously mentioned, it is not illegal to be a yakuza member in Japan, but the YEOs marginalize the yakuza by prohibiting non-yakuza from associating with them. Since membership in the yakuza is essentially an underlying crime opportunity, the YEOs can be interpreted as an effort to reduce underlying criminal opportunity structures that allow yakuza activities to persist.

While non-yakuza are prohibited from providing benefits that may aid in yakuza activities, they nevertheless may be at a high risk of experiencing retaliation from yakuza members if they comply with the prohibition. This fear of retaliation may tempt the nonyakuza into associating with yakuza members. According to Buerger (2014), one of the fundamental challenges of TPP is overcoming such resistance. To aid in implementation, the YEOs impose penalties on non-yakuza who associate with yakuza members. This coer-

\footnotetext{
${ }^{2}$ In 2007, the Minister of Justice announced guidelines to reduce victimization (e.g., citizens, corporations, and governments) by the yakuza. The guidelines emphasize the importance of avoiding associating with the yakuza in any way, given that the association between the yakuza and non-yakuza may serve as income sources for the yakuza. Since this announcement was made, strategies for combating the yakuza have sought to emphasize severing the association.
} 
cive engagement technique may create a dilemma for the non-yakuza. If they comply with the YEOs, they may face retaliation from the yakuza, but if they violate the prohibition, they may be subject to YEO-imposed penalties. For instance, business owners in violation of the YEOs' prohibition risk their names being revealed to the public, which may cost them their credibility and which may make it more difficult for them to transact with banks. They may also be prohibited from bidding on public construction projects. In addition, they may be subject to imprisonment and fines.

To better understand the partnership practice, we give an instance in which coercive techniques were used to implement the YEOs. The Onigiri Club is a golf club consisting of 70 construction companies in Fukuoka prefecture. The managers of nine construction companies of the Onigiri Club played golf in 2010. It was later discovered that they had played golf with the leaders of yakuza syndicates together. In 2011, the Fukuoka Police Department reported this fact to the local government of Fukuoka and announced the names of these construction companies on the website of the Fukuoka Police Department. Upon finding out, the local government of Fukuoka took measures against these nine construction companies and prohibited them from working on public construction projects. As a result, two out of the nine went bankrupt. Such a sanction served as a coercive technique that deterred third parties from violating the proscription of the YEOs.

This sanction is an illustration of the YEOs' concept of "society versus the yakuza." Only non-yakuza constructors who played golf with yakuza members experienced severe penalties; yakuza members themselves did not. By associating - even personally — with yakuza, nonyakuza may risk being labeled as persons having such a relationship with the yakuza. Such a relationship indicates that the yakuza are substantially involved in the person's management, and therefore the person could suffer from severe social sanction. In this image of the society versus yakuza, such "government-manufactured" ostracism coerces non-yakuza into doing what YEOs suggest is their duty as third parties.

It is, in general, difficult to quantify the actual enforcement levels of the YEOs. However, we believe that this concern does not present a serious problem in estimating the YEOs' effect. The National Police Agency reports the number of violators of the YEOs, and these numbers seem to be stable (with a slight increase from 62 to 71) during the period of our study. This by itself suggests that the YEOs are, at least to some extent, enforced. Of course, it is impossible to show the non-existence of the dark figures of crime. There may be more violators of the YEOs, but the possibility of dark figures does not nullify the effect of the YEOs. If, hypothetically, the YEOs had not been enforced properly and only a few, or even no, non-yakuza had obeyed the YEOs, then the YEOs would have had a negligible effect; in other words, the introduction of the YEOs would not change any variables as long 
as other factors were controlled. Thus, if the YEOs significantly reduce the number of yakuza members, we can interpret this effect as evidence that the YEOs are well enforced.

Finally, we note that the YEOs are prefecture-level ordinances. Japan consists of 47 prefectures, and prefectures are the first level of jurisdiction and administrative division. This is the unit of analysis in our study. TPP practices generally operate at micro-spatial levels, but YEOs are measured at the prefecture level. This is the unit of analysis we used in our study. When investigating TPP practices in relation to hot spot- or individual-level disorder and drug markets, finer spatial units are most appropriate, as they account for environmental and physical conditions in neighborhoods. In contrast, the YEOs consider social interaction between the yakuza and non-yakuza, which is independent of the spatial units used. The contents of the YEOs are slightly different from prefecture to prefecture, but the basic concepts remain the same across all the prefectures. ${ }^{3}$

\subsection{Hypotheses}

The Effect of the YEOs. The YEOs aim to increase the cost of belonging to the yakuza, thereby raising the incentive for yakuza members to defect from their yakuza syndicates. First, the YEOs aim to cause financial damage to the yakuza by eliminating their income flow from non-yakuza. Drawing on the rational choice theory of crimes (Becker, 1968), we argue that this financial damage increases the likelihood that yakuza members defect from yakuza syndicates because this makes it difficult for yakuza members to obtain money as they did before. Additionally, consistent with situational crime prevention approaches (Clark, 1997; Cornish and Clarke, 2003), prohibiting non-yakuza from renting apartments to the yakuza and from opening bank accounts for them makes the yakuza's lives difficult, thereby reducing underlying criminal opportunities for the yakuza's activities. Through these financial and non-financial channels, the YEOs increase the cost of belonging to the yakuza. Figure 1 shows the change in the number of yakuza members. ${ }^{4}$ The YEOs were

\footnotetext{
${ }^{3}$ There are some differences across prefectures. Under the YEOs, non-yakuza who make contracts are required to check whether the other parties to the contracts are related to yakuza. The relationship that has to be checked differs across prefectures. In a few prefectures, non-yakuza need to check only whether the other parties to contracts are yakuza members. Yet in Tokyo, non-yakuza need to check whether the other parties have been closely associated with the yakuza. This requirement in Tokyo is stringent, but in many other prefectures, non-yakuza are still required to ask the other parties to their contracts if at least five years have passed since they retired from their yakuza syndicates. This rule is often called a five-year rule.

${ }^{4}$ This figure is based on the data by National Police Agency (2015). The reported number of yakuza members is the number reported in December of each year. For readers' convenience, we report these numbers as the number of yakuza members in the subsequent years (e.g., the number in 2011 is the number as of December 2010). There are two types of yakuza members: regular members, who belong to particular yakuza syndicates; semi-regular members, who do not belong to but are allied with particular yakuza syndicates. Figure 1 plots the change in the total number.
} 
Figure 1: Change in Number of Yakuza Members

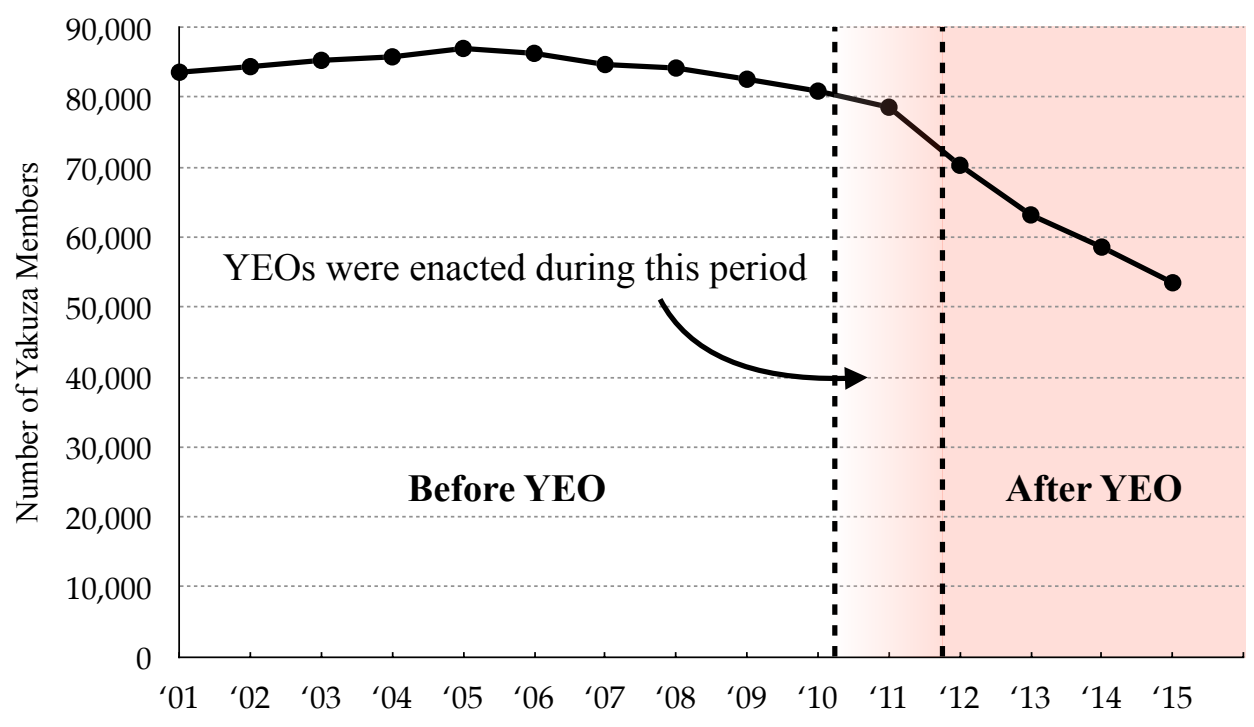

enacted during the period marked in the figure by the two dashed lines. ${ }^{5}$ The number of yakuza members had been stably more than 80,000 before the YEOs, but once the YEOs were enacted, the number of yakuza members dropped dramatically, with roughly 30,000 reductions in the five years. This is equivalent to an approximately $30 \%$ reduction. Our first interest is to identify the the effect of the YEOs on the number of yakuza members.

Hypothesis 1. The YEOs decrease the number of yakuza members.

Heterogeneity of the YEOs' Effect. Whether yakuza members defect may depend on the "strategic relationship" among yakuza syndicates. Like usual (legal) markets, illegal markets normally function under intense competition. Like other criminal organizations, yakuza syndicates are profit-maximizers, as the term economic yakuza indicates (Hill, 2003, 2004). Yakuza syndicates behave as economic organizations that engage in both legal and illegal business activities. It is then reasonable to expect that potential competition among yakuza syndicates crucially affects regional market conditions.

Crime syndicates can be considered to be rational and strategic in the sense that when they make a decision, they take into account how rival yakuza syndicates will respond (e.g., Dell, 2015). In the current context, yakuza syndicates choose their "power" strategically to gain advantages over the competition; that is, their rival yakuza syndicates. The question thus is: How should power be defined in this context? In usual (legal) markets, it is assumed that economic firms choose their capital and labor, where capital is often interpreted as the

\footnotetext{
${ }^{5}$ The reason that the enactment dates are spread over about two years is that the YEOs are prefecturelevel ordinances and the enactment dates vary from prefecture to prefecture.
} 
level of technology adopted and labor as the number of workers, and where capital is fixed in the short term. Since it usually takes time to change capital levels, it is fairly standard, in economics, to assume that only labor levels can be controlled in the short term (e.g., Mas-Colell et al., 1995). This observation carries over to our context. Since our analysis focuses on the short term, we assume that yakuza syndicates change only their labor force (i.e., their numbers of members). An immediate consequence of this assumption is that a yakuza syndicate attempts to keep its labor force large for potential competition against other yakuza syndicates. Another possible reason why a yakuza syndicate may attempt to keep its labor force large is that there may be high demand for the yakuza or yakuza activities (e.g., high demand for drugs or protection rackets). Such high demand may discourage yakuza members from resigning from their yakuza syndicates. In either case, it is suggested that a decrease in the labor force is disadvantageous to a given yakuza syndicate, especially if it is operating in a region with many rival yakuza syndicates. ${ }^{6}$

From this argument, we hypothesize that in more yakuza-concentrated regions (with higher YCI), yakuza syndicates need to maintain their power; otherwise, they would be more likely to be disadvantageous in (potential) competition against other yakuza syndicates. In contrast, in a less yakuza-concentrated regions (with lower YCI), yakuza syndicates have weaker incentives to maintain their power. That is, multiple yakuza syndicates, as strategic actors, mutually reinforce their power. This strategic relationship is called strategic complements in game theory; accordingly, the power (i.e., the number of yakuza members) will be clustered (Bulow et al., 1985). This observation is translated into more yakuza members retiring from yakuza syndicates if the yakuza syndicates are operating in less yakuza-concentrated regions under the YEOs. Indeed, as illustrated in Figure 2, the YCI distribution is regionally clustered (where the darker colored prefectures are exposed to higher concentrations of yakuza syndicates).

Hypothesis 2. The YEOs' effect on the number of yakuza members is stronger in less yakuza-concentrated regions (regions with lower YCI).

\footnotetext{
${ }^{6}$ To keep order, a yakuza syndicate may use violence against its members who violate its norms, even cutting off the offending members' fingers. In the yakuza world, finger chopping can represent punishment or sincere apology and remorse. This tradition has been on the decline in recent years, but it remains in some areas. In recent years, yakuza members have increasingly been forced to pay money as a penalty. If they cannot pay, they may be punished violently.
} 
Figure 2: Prefecture-level Yakuza Concentration Index

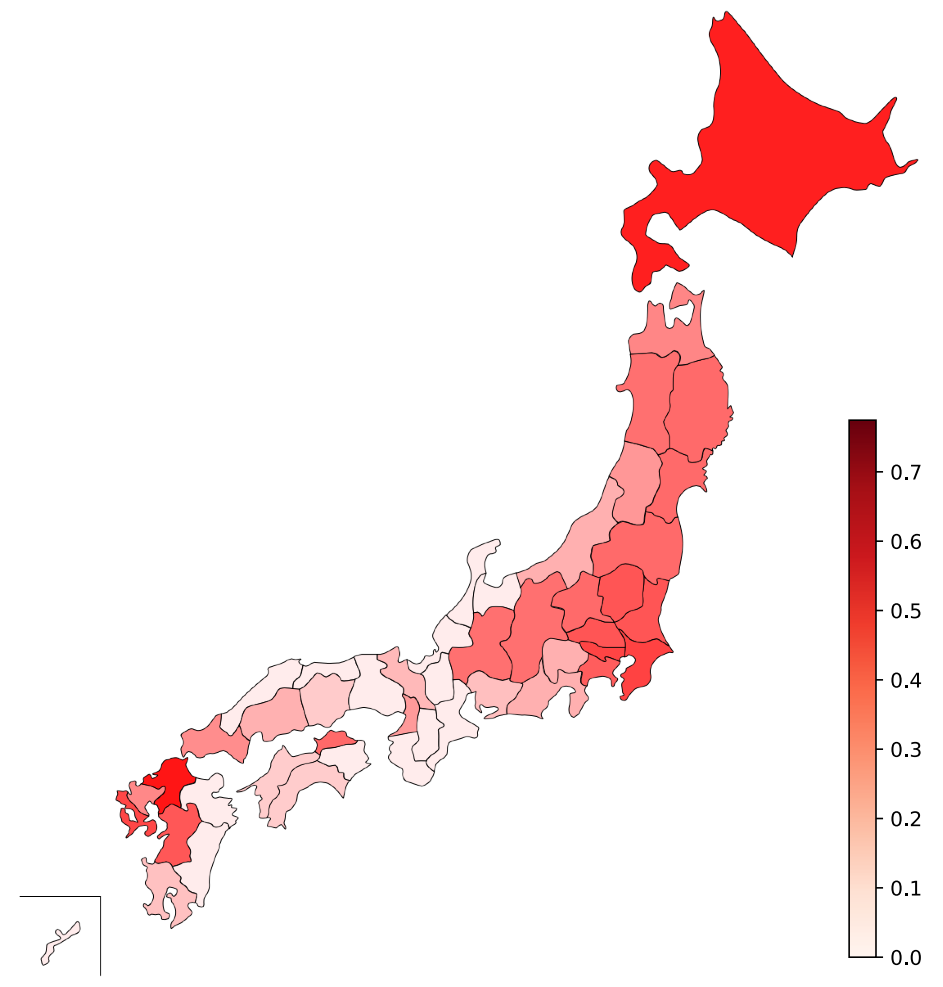

\section{Data and Identification Strategy}

\subsection{Data}

Enactment Dates of YEOs. The YEOs are prefecture-level ordinances, and the enactment dates vary across prefectures. The enactment dates are listed in Table $1 .^{7}$ While the majority of prefectures enacted the YEOs in April of 2011, the other prefectures enacted the YEOs between April of 2010 to January of 2012. To identify the YEOs' effect, we exploit the differences in the enactment timings of the YEOs across prefectures, while allowing the YEOs' effect to vary by YCI, as will be discussed in Section 3.2.

Yakuza Members. Since the National Police Agency (NPA) reports the number of yakuza members only at the national level, we requested prefecture-level data from the Prefectural Police Departments. According to the Japanese Organized Crime Division of the NPA, the

\footnotetext{
${ }^{7}$ In several prefectures, the YEOs were amended after their introduction. For example, Akita enacted YEOs in March 2011 and then amended them in July 2011. As we are interested in the TPP-like aspect of the YEOs, we define the enactment date as the date at which the clauses to regulate non-yakuza activity were incorporated. Accordingly, we define the Akita enactment date as July 2011. The YEOs were similarly amended in Tottori, Fukuoka, and Saga.
} 
Table 1: Enactment Dates of YEOs

\begin{tabular}{|c|c|c|c|c|c|c|c|c|}
\hline \multirow{2}{*}{$\frac{\text { Prefecture }}{\text { Hokkaido }}$} & \multicolumn{2}{|c|}{ Enactment } & \multirow{2}{*}{$\begin{array}{l}\text { Prefecture } \\
\text { Nagano }\end{array}$} & \multicolumn{2}{|c|}{ Enactment } & \multirow{2}{*}{$\begin{array}{l}\text { Prefecture } \\
\text { Okayama }\end{array}$} & \multicolumn{2}{|c|}{ Enactment } \\
\hline & Apr. & 2011 & & Sep. & 2011 & & Apr & 2011 \\
\hline Aomori & Jul. & 2011 & Shizuoka & Aug. & 2011 & Hiroshima & Apr & 2011 \\
\hline Iwate & Jul. & 2011 & Toyama & Aug. & 2011 & Yamaguchi & Apr & 2011 \\
\hline Miyagi & Apr. & 2011 & Ishikawa & Aug. & 2011 & Tokushima & Apr & 2011 \\
\hline Akita & Jul. & 2011 & Fukui & Apr. & 2011 & Kagawa & Apr & 2011 \\
\hline Yamagata & Aug. & 2011 & Gifu & Apr. & 2011 & Ehime & Aug. & 2010 \\
\hline Fukushima & Jul. & 2011 & Aichi & Apr. & 2011 & Kochi & Apr & 2011 \\
\hline Tokyo & Oct. & 2011 & Mie & Apr. & 2011 & Fukuoka & Apr & 2010 \\
\hline Ibaraki & Apr. & 2011 & Shiga & Aug. & 2011 & Saga & Jan. & 2012 \\
\hline Tochigi & Apr. & 2011 & Kуо & Apr. & 2011 & Nagasaki & Apr & 2010 \\
\hline Gunma & Apr. & 2011 & Osaka & Apr. & 2011 & Kumamoto & Apr & 2011 \\
\hline Saitama & Aug. & 2011 & Hyogo & Apr. & 2011 & Oita & Apr & 2011 \\
\hline Chiba & Sep. & 2011 & Nara & Jul. & 2011 & Miyazaki & Aug. & 2011 \\
\hline Kanagawa & Apr. & 2011 & Wakayama & Jul. & 2011 & Kagoshima & Apr & 2010 \\
\hline Nigata & Aug. & 2011 & Tottori & Apr. & 2011 & Okinawa & Oct. & 2011 \\
\hline Yamanashi & Apr. & 2011 & Shimane & Apr. & 2011 & & & \\
\hline
\end{tabular}

police draw on many sources to confirm whether a member has defected from his yakuza syndicate. For example, the police take into account expulsion letters and interviews with other members or arrested members. Expulsion letters are notifications issued by a yakuza syndicate when its member defects from the syndicate, to prevent the defecting member from transferring to another yakuza syndicate. However, the notifications may not be enough for the police to count the individual as a yakuza dropout. The police need supporting evidence, which can be obtained through the investigation of yakuza offices and the interviews. These processes allow the police to track the actual numbers of yakuza members.

We obtained data on the number of yakuza members on 37 out of 47 prefectures from 2008 to 2013. Our main analysis uses the data with missing values, but we test the robustness of our results using the multiple imputation procedure in Appendix A. The provided data contain the number of yakuza members in each of these prefectures at the yearly level. Our main analysis is based on the year-level panel data, but we also provide estimates using month-level imputed data by linear interpolation in Appendix A. The outcome variable of interest is the yakuza rates, which are defined as the number of yakuza members per 100,000 residents. The average yakuza rate across all the prefectures is 45 . During the period from 2008 to 2013 , the average yakuza rate declined from 52 to 37 , or approximately by $29 \%$. The number of our observations is 207 (37 prefectures $\times 6$ years, minus approximately the $5 \%$ missing data in the 37 prefectures). 
Yakuza Concentration Index. To construct a prefecture-level concentration index of yakuza syndicates - called the Yakuza Concentration Index (YCI) - we use two kinds of data: (i) the number of yakuza syndicates operating in each prefecture; and (ii) the number of members in each yakuza syndicate. As explained below, to construct the YCI we use the information prior to the enactment of the YEOs across prefectures. Both data are available in National Police Agency (2009).

We define prefecture-level YCI in a manner similar to the Hirschman-Herfindahl index. Let $G$ be the set of all 21 (designated) yakuza syndicates, and let $s_{p g}$ be the "share" of yakuza syndicate $g \in G$ in prefecture $p$, which is defined below. It would be desirable to use data on the number of members of each yakuza syndicate in each prefecture to calculate the share, but such data do not exist. We thus need to estimate these figures. For now, let us assume that the members of each yakuza syndicate $g$ are distributed over the prefectures where the syndicate operates proportionally to the population of each of the prefectures. (To examine the robustness of our estimation, we will modify this assumption in Appendix A.) Since we know the total number of members of each yakuza syndicate, we can calculate the share $s_{p g}$ under this assumption. Let $P_{g}$ be the set of prefectures where yakuza syndicate $g$ operates, and let $q_{p}$ be the population in prefecture $p$. For a yakuza syndicate $g$, the population ratio of prefecture $p \in P_{g}$ to all the prefectures in which yakuza syndicate $g$ operates equals $q_{p} / \sum_{p^{\prime} \in P_{g}} q_{p^{\prime}}$. Hence, the estimated number of members of yakuza syndicate $g$ in prefecture $p$, denoted $N_{g p}$, is the total number of members of yakuza syndicate $g$ times the population ratio $q_{p} / \sum_{p^{\prime} \in P_{q}} q_{p^{\prime}}$. We define the share of yakuza syndicate $g$ in prefecture $p$ by $s_{p g}=N_{g p} / \sum_{g^{\prime} \in G_{p}} N_{g^{\prime} p}$ if $g \in G_{p}$ and $s_{p g}=0$ if $g \notin G_{p}$, where $G_{p}$ is the set of yakuza syndicates that operate in prefecture $p$. By definition, $0 \leq s_{p g} \leq 1$ and $\sum_{g} s_{p g}=1$ for each $p, g$ (since there is at least one yakuza syndicate in every prefecture). Given these shares, we define the YCI of prefecture $p$ by $Y C I_{p}=1-\sum_{g \in G} s_{p g}^{2}$. Note that $Y C I_{p}=0$ if there is only one syndicate in prefecture $p$ and $Y C I_{p}$ increases in the number of yakuza syndicates in prefecture $p$.

We treat the YCI as time-independent, measured using the data prior to the enactment of the YEOs. The reason why we define the YCI in this manner is to avoid potential statistical biases. To see this, suppose that the YCI is time-dependent. If the YEOs reduce yakuza members, then the YCI may be affected by the YEOs and is considered as a post-treatment covariate, a variable that is affected by a treatment. From a causal inference standpoint, conditioning on a post-treatment covariate can induce post-treatment bias, which estimates treatment effects among a group, whose post-treatment covariate is not affected by treatment (e.g., Rosenbaum, 1984; Montgomery et al., 2018). By defining the YCI in the said manner, 
we can avoid this problem. ${ }^{8}$

Control Variables. We control for a host of observed covariates. First, we control for demographic and socioeconomic variables: the proportion of males, the proportion of individuals aged 15-24, the proportion of individuals aged 25-34, the proportion of individuals aged over 65, the proportion of foreign people, population density, the unemployment rate, welfare recipients per 1,000 inhabitants, and GDP. We also control for crime variables: police per 1,000 inhabitants, the log of overall crime rates (violent crime and property crime). The data on demographic, socioeconomic, and police variables are publicly available on e-Stat (a portal site for Japanese Government Statistics). See Appendix D for the summary statistics of these control variables.

\subsection{Identification Strategy}

Difference-in-Differences Strategy. We discuss the empirical strategies whereby we isolate the YEOs' effect on the yakuza. In the absence of randomized control trials, it is challenging to identify the YEOs' effect. Naïve comparison of outcomes between prefectures with and without YEOs may be misleading and the estimates may be biased because those prefectures are likely to be different at both observable and unobservable levels. In the context of the current study, the timing of the YEOs' enactment may constitute non-random selection. For example, if the rise of yakuza activity is a major concern in a particular prefecture, the YEOs may be more likely to be introduced in that prefecture than in other prefectures where yakuza activity is not a major issue. Thus, the construction of appropriate counterfactual groups is necessary to estimate the YEOs' effect. We apply a difference-indifferences (DiD) estimation, which compares (i) outcomes before and after the introduction of the YEOs and (ii) outcomes between prefectures that have introduced the YEOs and prefectures that have not. In particular, we exploit time variations in the enactment dates of the YEOs. Moreover, we allow for treatment effect heterogeneity by a cross-sectional variation of YCI. Taken together, our main regression model is:

$$
y_{p t}=\beta_{1} Y E O_{p t}+\beta_{2} Y E O_{p t} \times Y C I_{p}+\eta X_{p t}+\mu_{p}+\xi_{t}+\sum_{r \in R} \delta_{p r} \rho_{r} t+\varepsilon_{p t} .
$$

\footnotetext{
${ }^{8}$ In Appendix A, we conduct several robustness checks using alternative indices. First, we use a timedependent YCI. Second, we use alternative definitions of yakuza shares $s_{p g}$ and a resulting YCI. Third, we use alternative indices for the regional competition among rival yakuza syndicates. Our empirical results are robust to all these specifications.
} 
Here, $y_{p t}$ is the log of yakuza rates, which we define as the number of yakuza members per 100,000 inhabitants in prefecture $p$ at time $t$. $Y E O_{p t}$ is a treatment dummy that equals 1 if the YEOs are in effect in prefecture $p$ at time $t$ and 0 otherwise. $Y C I_{p}$ is the YCI of prefecture $p$. For the reason discussed above, we treat the YCI as a time-independent variable constructed from the data prior to the enactment of the YEOs. $Y E O_{p t} \times Y C I_{p}$ allows for heterogeneity of the effect of the YEOs with respect to the YCI. $X_{p t}$ are controls. While we include a host of time-dependent covariates, we examine the robustness of the results to ensure that post-treatment bias is not a severe issue in Appendix A. $\mu_{p}$ is a prefecture fixed effect, which captures time-invariant unobservables, such as the yakuza culture and non-yakuza individuals' attitudes toward the yazuka. $\xi_{t}$ is a year fixed effect, which controls for common time-specific effects on all prefectures. $\sum_{r} \delta_{p r} \rho_{r} t$ captures region-specific time trends, which capture regional unobservables that vary over time. It is important to capture such regional unobservables since the YCI are regionally clustered (Figure 2). In this study, Japan is divided into seven regions: Hokkaido-Tohoku, Kanto, Chubu, Kansai, Chugoku, Shikoku, and Kyushu-Okinawa. Let $R$ be the set of these regions. $\delta_{p r}$ is a treatment dummy that equals 1 if prefecture $p$ is in region $r$ and 0 otherwise. $\rho_{r}$ is a region-specific time trend. $\varepsilon_{p t}$ is an idiosyncratic error. We use weighted least squares. Standard errors are clustered at the prefecture level to adjust for serial correlation within the same prefecture (Bertrand et al., 2004).

Event-Study Analysis. We study the dynamics of the YEOs' effects on the outcome by examining the three years before the enactment of the YEOs and the two years following the YEOs' enactment. This study design is referred to as an event-study design (Wing et al., 2018). It has two purposes. First, we indirectly test the parallel trend assumption by including leads for treatment indicators (before the YEOs). The parallel trend assumption is the identification assumption for the DiD design. It states that in the absence of treatment, treated and control groups follow similar trends concerning the outcome of interest (e.g., Angrist and Pischke, 2008). This assumption could be violated, however, if the YEOs' enactment reflected public concern about the high levels of yakuza activity. If the parallel trend assumption holds, the coefficients for the years before the YEOs' enactment should be small in magnitude or close to zero. Thus, this exercise serves as a placebo test. Second, we examine whether the YEOs' effects persist some time after the YEOs' enactment by including lagged treatment indicators (after the YEOs). The lagged indicators allow us to explore whether a decrease in the yakuza rates persists after the YEOs' enactment. If the YEOs' effects are persistent, the coefficients for the years following the YEOs' enactment should be large in magnitude and statistically significant. 
Here is the regression model for the event-study design:

$$
y_{p t}=\sum_{\tau=-2}^{3} \alpha_{\tau} Y E O_{p, t+\tau}^{\prime}+\beta Y E O_{p t} \times Y C I_{p}+\eta X_{p t}+\mu_{p}+\xi_{t}+\sum_{r \in R} \delta_{p r} \rho_{r} t+\varepsilon_{p t}
$$

with normalization $\alpha_{1}=0$. Following Autor (2003), let the treatment indicators for 1-2 leads and 1 lag of the YEOs take the value of 1 for the relevant year and the value of 0 otherwise. Let $Y E O_{p, t-2}^{\prime}=1$ for all $t$ two or more years later than the YEOs' enactment in prefecture $p$ (a 2-year or more lag indication), and let $Y E O_{p, t+3}^{\prime}=1$ for all $t$ two or more years earlier than the YEOs' enactment in prefecture $p$ (a 3-year or more lead indicator). We impose a parameter constraint on the one-year lead treatment indicator, which then serves as a reference year. Therefore, estimates for other lead and lag indicators are interpreted as the effects of the YEOs in comparison to this reference period. That is, the coefficient $\alpha_{\tau}$ measures the effect of the $(-\tau)$-year lag effect of the YEO if $\tau<0$ and the $\tau$-year lead effect if $\tau>0$, in comparison to $\tau=1$.

\section{Results}

\subsection{The Effect of the YEOs on Yakuza Members}

We study the YEOs' effect on the numbers of yakuza members. Recall that our outcome is the log of yakuza rates (i.e., the number of yakuza members per 100,000 inhabitants), so that the interpretation is a percentage change as a response to the YEOs. In Table 2, we report our estimates. We consider the following four specifications: Column (1) no region-specific trends; Column (2) region-specific linear trends; Column (3) region-specific quadratic trends; and Column (4) both linear and quadratic trends. The coefficients of the YEOs are significantly negative in all these specifications. Note that they equal the YEOs' effect evaluated at $Y C I_{p}=0$. In other words, in prefectures with one yakuza syndicate, the YEOs decrease the yakuza rates by approximately 15-20\% depending on the specification. From 2008 to 2013, the yakuza rates declined approximately by $32 \%$ in prefectures with YCI $=$ zero. Therefore, our estimates suggest that the YEOs account for 47-59\% of the reduction in yakuza rates in prefectures with $\mathrm{YCI}=$ zero during this period. The coefficients of $Y E O_{p t} \times Y C I_{p}$ are significantly positive, which suggests that the YEOs' effect decreases as the YCI increases. The total effect of the YEOs in prefecture $p$ is given by $\beta_{1}+\beta_{2} Y C I_{p}$. The nationwide total effect is obtained by replacing $Y C I_{p}$ with its nationwide average of 0.392 . Using this formula, we find that the YEOs reduce the yakuza rates by approximately 5-7\%. Given that the yakuza rates on average decreased by $29 \%$ from 2008 to 2013, our estimates 
suggest that the YEOs account for approximately 17-24\% of the recent reduction.

Based on the specification in Column (4), Figure 3 illustrates the heterogeneity of the YEOs' effect by the YCI in two ways. First, the solid line, together with the gray band, indicates the marginal effect of the YEOs on the yakuza rates with the $95 \%$ CIs, when we treat the YCI as a continuous variable. Second, the two dots, with the black dashed lines, indicate the marginal effect of the YEOs on the yakuza rates evaluated at the low YCI (less than or equal to the median) and at the high YCI (greater than the median). ${ }^{9}$ These results are consistent across both specifications in that the effect of the YEOs is greater in prefectures with lower YCI. Because the two point estimates indicated by the dots and the dashed lines are on the solid line corresponding to the regression (1), it is suggested that the two specifications are consistent with each other (Hainmueller et al., 2019).

\subsection{Event-Study Analysis}

Figure 4 reports the estimates of the event-study analyses with $90 \%$ confidence intervals. The left panel illustrates the YEOs' effect on the yakuza rates conditional on the YCI taking the value of zero. Analogously, the right panel illustrates the YEOs' effect conditional on the YCI taking the mean value. For the purpose of simplicity, we transform the YCI to the corresponding grand-mean centered variables and replace the YCI in equation (2) with the grand-mean centered YCI. ${ }^{10}$ As illustrated in Figures 3, the YEOs' effect decrease in the YCI and thus are not statistically significant at high YCI values. Therefore, we only provide graphical evidence up to the mean value of the YCI. Recall that this analysis has two purposes. First, it examines the trend of the outcome in years leading to the enactment of the YEOs by including the lead treatment indicators, labeled as "before YEO" in the figures. If the parallel trends assumption is satisfied, the coefficients of the lead treatment indicators should be close to zero. Since the future treatment status (i.e., the lead treatment indicators) should have no significant effects if the treatments had causal effects, the null effects of the lead treatment indicators serve as a placebo test. Second, the analysis examines the trend of the outcome in years following the enactment of the YEOs by including the lag treatment indicators, labeled as "after YEO" in the figures. This explores whether the YEOs effect persist for the 2 years following the YEOs' enactment.

${ }^{9}$ The represented estimates correspond to the estimates of $\delta_{1}$ and $\delta_{2}$ in the following regression:

$$
y_{p t}=\delta_{1} Y E O_{p t} \times \operatorname{Low}_{p}+\delta_{2} Y E O_{p t} \times H i g h_{p}+\eta X_{p t}+\mu_{p}+\xi_{t}+\sum_{r \in R} \delta_{p r} \rho_{r} t+\varepsilon_{p t},
$$

where $L_{0 w}$ denotes the low YCI (less than or equal to the median) and High $h_{p}$ denotes the high YCI (greater than the median). This equation does not include the main term of the YEOs to avoid multicollinearity.

${ }^{10}$ That is, we take the mean of the YCI variables and subtract this mean from each YCI variable. 
Table 2: The Effect of the YEOs on Yakuza Rates

\begin{tabular}{lcccc}
\hline \hline \multicolumn{1}{c}{$(1)$} & $(2)$ & $(3)$ & $(4)$ \\
\hline Dependent Variable: In Yakuza Rates & & & \\
\multicolumn{1}{c}{} & & & \\
YEO & $-0.222^{* * *}$ & $-0.163^{* * *}$ & $-0.174^{* * *}$ & $-0.162^{* * *}$ \\
& $(0.048)$ & $(0.053)$ & $(0.052)$ & $(0.054)$ \\
YEO $\times$ YCI & $0.384^{* * *}$ & $0.258^{* * *}$ & $0.273^{* * *}$ & $0.272^{* * *}$ \\
& $(0.077)$ & $(0.077)$ & $(0.077)$ & $(0.080)$ \\
& & & & \\
Overall Effects & $-0.071^{* *}$ & $-0.062^{* *}$ & $-0.067^{* *}$ & $-0.055^{*}$ \\
& $(0.023)$ & $(0.029)$ & $(0.029)$ & $(0.029)$ \\
& & & & \\
\hline Adjusted R-squared & 0.978 & 0.982 & 0.982 & 0.982 \\
Control Variables & $\checkmark$ & $\checkmark$ & $\checkmark$ & $\checkmark$ \\
Prefecture Fixed Effects & $\checkmark$ & $\checkmark$ & $\checkmark$ & $\checkmark$ \\
Time Fixed Effects & $\checkmark$ & $\checkmark$ & $\checkmark$ & $\checkmark$ \\
Region-specific Trends & No & Linear & Quadratic & Both \\
Observations & 207 & 207 & 207 & 207 \\
\hline
\end{tabular}

Notes: The yakuza rates are the number of yakuza members per 100,000 inhabitants. Control variables are the proportion of males, the proportion of individuals aged 15-24, the proportion of individuals aged 25-34, the proportion of individuals aged over 65 , the proportion of foreign people, population density, the unemployment rate, welfare recipients per 1,000 inhabitants, GDP, police per 1,000 inhabitants, the log of overall crime rates. Data Sources: the data on the number of yakuza members are from prefectural police departments, and the data on other control variables from e-Stat. Standard errors in parentheses are clustered at the prefecture level. Significance at the $1 \%, 5 \%$, and $10 \%$ levels indicated by $* * *, * *$, and ${ }^{*}$, respectively.

Figure 4 illustrates that the coefficients $\alpha_{\tau}$ for the lead treatment indicators (i.e., before YEO) are close to zero, but as soon as the YEOs are enacted, the coefficients $\alpha_{\tau}$ for the lagged treatment indicators (i.e., after YEO) decrease sharply. That is, the coefficients of the lead treatment indicators are not statistically significant. The pretreatment trends by themselves appear to be unable to explain the change of the yakuza rates. It supports the parallel trend assumption in our DiD analyses.

\subsection{Permutation Test}

To ensure that the estimated effect of the YEOs is causal, rather than spurious, we conduct a permutation test (e.g., Abadie et al., 2010, 2015). In this exercise, we randomly vary the enactment dates of the YEOs across prefectures, and we call the randomly assigned enactment dates placebo treatments. The intuition behind this exercise is that if the estimated 
Figure 3: Marginal Effect of YEOs on Yakuza Rates with 95\% CIs

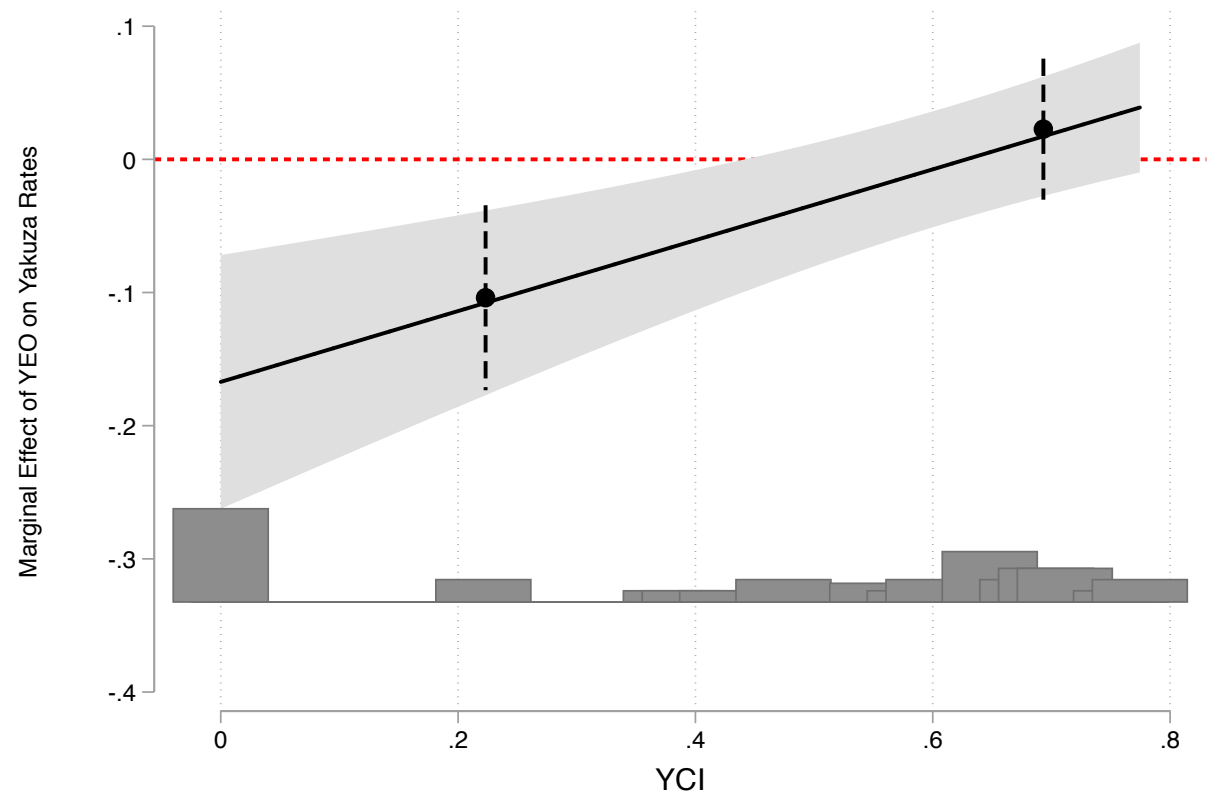

Notes: The yakuza rates are the number of yakuza members per 100,000 inhabitants. Histogram: the distribution of YCI along the x-axis. Estimates indicated by the solid line and the gray band: the marginal effect of the YEOs on the yakuza rates by the continuous YCI with 95\% CIs. Two point estimates indicated in the dots and the dashed lines: the marginal effect of the YEOs on the yakuza rates by low YCI (less than or equal to the median) and high YCI (greater than the median) with 95\% CIs. Control variables: see Table 2. Data Sources: see Table 2.

effect of the YEOs is causal, then the estimates that are derived from the placebo treatments should not have significant effects. For this test, we redraw placebo treatments randomly and reestimate placebo treatment effects. We iterate this process 10,000 times.

Figure 5 shows the resulting distributions of the estimated placebo coefficients. The top panel shows the result when YCI is evaluated at zero, and the bottom panel shows the result when YCI is evaluated at the mean. For the latter, to simplify the computation, we re-estimate the coefficient of the YEOs in equation (1), using the grand-mean centered YCI. In each panel, the dashed red line indicates the lower $5 \%$ of the distribution of the placebo coefficients: -0.004 when the YCI takes the value of zero (top panel) and -0.019 when the YCI takes the mean value (bottom panel). Our preferred estimates of the YEOs taken from Column (4) in Table 2 indicate -0.162 when the YCI takes the value of zero and -0.055 when the YCI takes the mean value. If the YEOs' effect is causal, the estimated coefficients reported in Table 2 should be larger than the placebo coefficients and thus be in the left tail of the distribution of the placebo coefficients. Indeed, this is exactly what Figure 5 shows. 
Figure 4: Event-Study Analysis of YEOs' Effect on Yakuza Rates

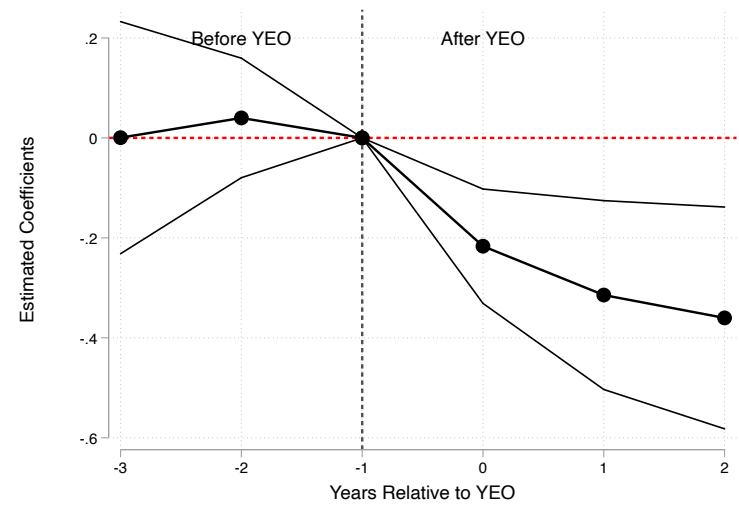

YEOs' Effect Evaluated at YCI = Zero

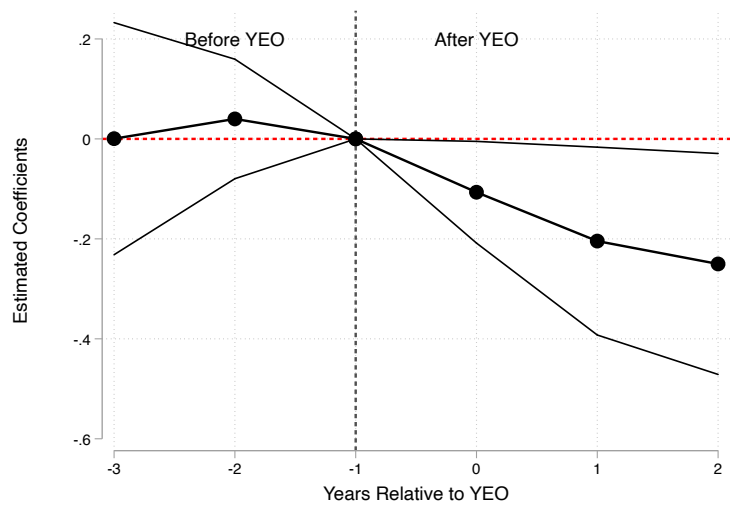

YEOs' Effect Evaluated at YCI $=$ Mean

Notes: The yakuza rates are the number of yakuza members per 100,000 inhabitants. Control variables: see Table 2. Data Sources: see Table 2. Standard errors in parentheses are clustered at the prefecture level.

Thus, it is unlikely that the estimated effects of the YEOs are driven by randomness or idiosyncrasy.

\section{Discussion and Conclusion}

Our study contributes to the literature on TPP as well as organized crime and provides several implications. First, we study the effect of TPP on organized crime. Evidence of TPP's effects on street-level crime has been found (Weisburd and Majmundar, 2018), but its effects on organized crime are not well known. The TPP literature has paid attention to street-level crime because the systematic assessment of TPP practices has been devoted to street-level crime, but it is recognized that further research is necessary to understand the use and effectiveness of TPP in other areas of regulation, as stated in Mazerolle and Ransley (2006). Moreover, studies on multi-agency approaches to organized crime generally focus on partnerships across agencies and the development thereof (Bjelland and Vestby, 2017; Kleemans and Huisman, 2015). We also note that there are strategies similar to the YEOs in that they prohibit non-criminal citizens to associate with members of criminal organizations (Nelen and Siegel, 2017). However, our study is the first to evaluate the effect of a TPP-related strategy on the second party (the yakuza in our case).

Our evidence suggests that the YEOs are an effective countermeasure against the yakuza. The number of yakuza members dropped by approximately 30\% during the period of our 
Figure 5: Permutation Test: Yakuza Rates
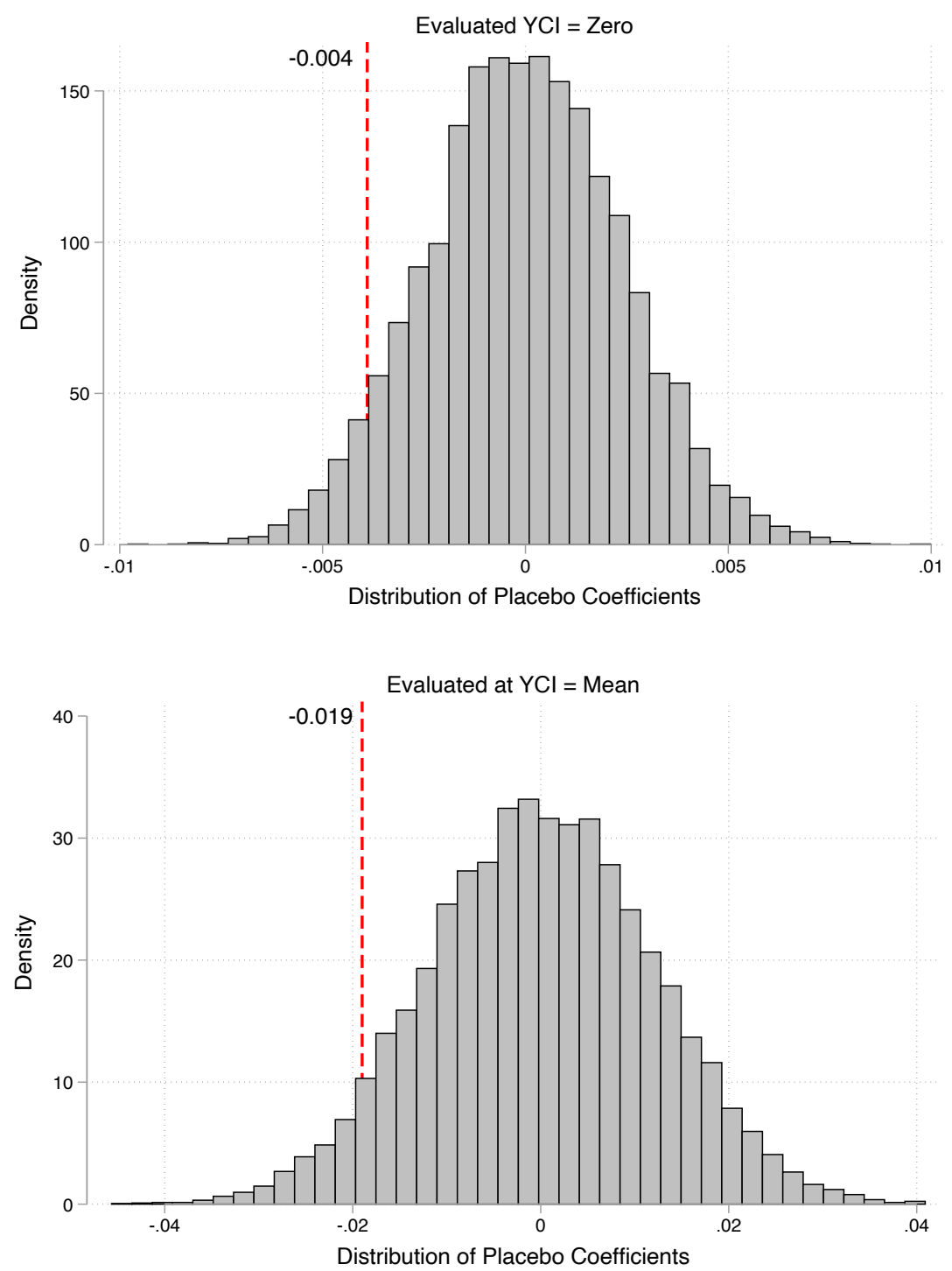

Notes: Dashed red line: Estimates derived from placebo treatments. Estimated effects of the YEOs: -0.162 (evaluated YCI $=$ Zero); -0.055 (evaluated YCI $=$ Mean). Permutation test: 10,000 times. Control variables: see Table 2. Data Sources: see Table 2

study; our estimates suggest that the YEOs account for roughly $26 \%$ of this recent reduction in the number of yakuza members. This result is notable, given that third parties may not be willing to cooperate with the police due to fear of potential retaliation by criminal organizations. As in the case of the Onigiri Club, under the coercive techniques utilized by the YEOs, the cost of violating the YEOs may be greater (for third parties) than the potential cost of retaliation by criminal organizations. We have seen that the YEOs are, 
at least conceptually, related to TPP characterized by coercive techniques. Given this, our results support the effectiveness of TPP against organized crime.

Second, our results about the heterogeneity of the YEOs' effect by the YCI provide both theoretical and policy implications. The results suggest that the effectiveness of the YEOs may be affected by the strategic relationship between yakuza syndicates. When criminal organizations compete with one another, these relationships may serve as a powerful tool to leverage in the competition. Specifically, we argue that concentrated attack on a few criminal organizations is more effective than dilute attack on many. This is because the concentrated attack is expected to weaken a particular criminal organization, which, through strategic relationship, discourages neighboring rival criminal organizations from maintaining (costly) strategic power, such as workforce. In other words, the concentrated attack is expected to cause the domino effect, via the strategic relationship, that weakens more criminal organizations.

Third, our study contributes to research on organized crime. Quantitative evidence of interventions against organized crime is scarce because of the difficulty in measuring organized crime reduction (Levi and Maguire, 2004). Existing quantitative analyses of criminal organizations mainly focus on violence to understand how their activities change as a response to interventions against them (e.g., Dell, 2015; Dickenson, 2014; Phillips, 2015). In contrast, we use unique data on the change in the number of yakuza members to directly estimate the effect of interventions against organized crime on the number of organized crime participants.

Our results survive a variety of robustness tests. They are robust to an alternative identification assumption, post-treatment bias, and alternative indices for regional competition among yakuza syndicates. They also pass a recent DiD correction method (Goodman-Bacon, 2018). See Appendix A. While the robustness exercises increase internal validity, we caution that our estimates cannot be interpreted as strictly causal in the absence of randomized control trials.

We note several limitations of our research design. First, local governments' decisions to enact the YEOs may not be completely at random. For instance, the local governments may take into consideration local yakuza activity. Fukuoka is the first prefecture that enacted the YEO because of elevated yakuza conflicts. That being said, since there was a nationwide movement to introduce the YEOs, we believe that the local governments likely had little discretion. Moreover, our placebo test in the event-study design also suggests that the treatment effect is not driven by the preexisting conditions of the number of yakuza members. Second, our DiD application, like most existing applications, exploits variation across groups of units that receive treatment at different times. In our context, as the YEOs were 
introduced at different times in different prefectures, there might be poor cross-sectional variation for prefectures that enacted the YEOs at later times. Third, our analysis focuses on the short-term effects of the YEOs. While our event-study analysis shows that the YEOs' effect persists at least 2 years after the enactment, our paper does not analyze the long-term effects of the YEOs, simply because of the data limitation. Further analysis, based on longer periods, needs to be carried out to ensure external validity.

Despite these limitations, our study suggests that the principles of TPP are generally an effective countermeasure against organized crime, though they may result in unintended consequences. Further research on this topic is necessary to assess the external validity of the effects of TPP on organized crime.

\section{References}

Abadie, Alberto, Alexis Diamond, and Jens Hainmueller. 2010. "Synthetic control methods for comparative case studies: Estimating the effect of California's tobacco control program." Journal of the American statistical Association 105:493-505.

Abadie, Alberto, Alexis Diamond, and Jens Hainmueller. 2015. "Comparative politics and the synthetic control method." American Journal of Political Science 59:495-510.

Angrist, Joshua D and Jörn-Steffen Pischke. 2008. Mostly harmless econometrics: An empiricist's companion. Princeton university press.

Autor, David H. 2003. "Outsourcing at will: The contribution of unjust dismissal doctrine to the growth of employment outsourcing." Journal of Labor Economics 21:1-42.

Ayling, Julie. 2017. "Combating organized crime Aussie-style: from law enforcement to prevention." In Contemporary Organized Crime, pp. 189-212. Springer.

Bang, Heejung and James M Robins. 2005. "Doubly robust estimation in missing data and causal inference models." Biometrics 61:962-973.

Becker, Gary S. 1968. "Crime and punishment: An economic approach." Journal of Political Economy 76:169-217.

Bertrand, Marianne, Esther Duflo, and Sendhil Mullainathan. 2004. "How much should we trust differences-in-differences estimates?" Quarterly Journal of Economics 119:249-275.

Bjelland, Heidi Fischer and Annette Vestby. 2017. "It's about using the full sanction catalogue': on boundary negotiations in a multi-agency organised crime investigation." Policing and society $27: 655-670$.

Buerger, Michael E. 2014. "Third-Party Policing." In Encyclopedia of Criminology and Criminal Justice, pp. 5221-5232. Springer.

Bulow, Jeremy I, John D Geanakoplos, and Paul D Klemperer. 1985. "Multimarket oligopoly: Strategic substitutes and complements." Journal of Political Economy 93:488-511. 
Clark, Ronald V. 1997. "Situational crime prevention." Successful Case Studies, Harrow and Heston Publishers, 2th Edition, Guilderland, New York .

Cornish, Derek Blaikie and Ronald V Clarke. 2003. "Opportunities, precipitators and criminal decisions: A reply to Wortley's critique of situational crime prevention." Crime prevention studies 16:41-96.

Dell, Melissa. 2015. "Trafficking networks and the Mexican Drug War." American Economic Review 105:1738-1779.

Dickenson, Matthew. 2014. "The impact of leadership removal on Mexican drug trafficking organizations." Journal of Quantitative Criminology 30:651-676.

Goodman-Bacon, Andrew. 2018. "Difference-in-differences with variation in treatment timing." Technical report, National Bureau of Economic Research.

Hainmueller, Jens, Jonathan Mummolo, and Yiqing Xu. 2019. "How much should we trust estimates from multiplicative interaction models? Simple tools to improve empirical practice." Political Analysis 27:163-192.

Hill, Peter. 2004. "The changing face of the Yakuza." Global Crime 6:97-116.

Hill, Peter BE. 2003. The Japanese mafia: Yakuza, law, and the state. Oxford University Press.

Kleemans, Edward R and Wim Huisman. 2015. "Multi-agency approaches in 'criminogenic'settings: the case of the Amsterdam Red Light District." Crime, law and social change 64:247-261.

Levi, Michael and Mike Maguire. 2004. "Reducing and preventing organised crime: An evidencebased critique." Crime, Law and Social Change 41:397-469.

Mas-Colell, Andreu, Michael Dennis Whinston, Jerry R Green, et al. 1995. Microeconomic theory, volume 1. Oxford university press New York.

Mazerolle, Lorraine, Elizabeth Eggins, and Angela Higginson. 2013. "Third party policing for reducing crime and disorder: A systematic review." The Campbell Collaboration .

Mazerolle, Lorraine and Janet Ransley. 2004. "Third party policing: prospects, challenges and implications for regulators." Regulation: Enforcement and Compliance, Research and public policy series pp. 61-76.

Mazerolle, Lorraine and Janet Ransley. 2006. Third party policing. Cambridge University Press.

Milhaupt, Curtis J and Mark D West. 2000. "The dark side of private ordering: an institutional and empirical analysis of organized crime." The University of Chicago Law Review pp. 41-98.

Montalvo, Jose G and Marta Reynal-Querol. 2005. "Ethnic diversity and economic development." Journal of Development Economics 76:293-323.

Montgomery, Jacob M, Brendan Nyhan, and Michelle Torres. 2018. "How conditioning on posttreatment variables can ruin your experiment and what to do about it." American Journal of Political Science 62:760-775.

National Police Agency. 2009. "Trends in the Yakuza (Boryokudan Josei).” . 
National Police Agency. 2014. "Trends in the Yakuza (Boryokudan Josei)." .

National Police Agency. 2015. "White Paper on Police: Special Issue on the Yakuza (Keisatsu Hakusho)." .

Nelen, Hans and Dina Siegel. 2017. Contemporary Organized Crime: Developments, Challenges and Responses, volume 16. Springer.

Peters, Maaike and Antonius Spapens. 2015. "The administrative approach in the Netherlands." Administrative approaches to prevent and tackle crime: Legal possibilities and practical application in EU Member States pp. 265-306.

Phillips, Brian J. 2015. "How does leadership decapitation affect violence? The case of drug trafficking organizations in Mexico." Journal of Politics 77:324-336.

Ramseyer, J Mark. 2016. "Nuclear Power and the Mob: Extortion in Japan." Journal of Empirical Legal Studies 13:487-515.

Rosenbaum, Paul R. 1984. "The consequences of adjustment for a concomitant variable that has been affected by the treatment." Journal of the Royal Statistical Society: Series A (General) 147:656-666.

Rubin, Donald B. 1987. Multiple imputation for nonresponse in surveys, volume. John Wiley \& Sons.

Webster, Julianne. 2015. "Effective third-party policing partnerships or missed opportunities?" Policing and society 25:97-114.

Weisburd, David and Malay K. Majmundar. 2018. Proactive policing: Effects on crime and communities. National Academies Press.

Wing, Coady, Kosali Simon, and Ricardo A Bello-Gomez. 2018. "Designing difference in difference studies: best practices for public health policy research." Annual review of public health 39. 


\section{ONLINE APPENDIX (Not for Publication)}

\section{A Robustness Check}

We demonstrate the robustness of our empirical results. All these results are reported in Table A1.

Estimation Method: Column (1). We test the robustness to estimation methods. We report the OLS estimation results. Regressors are no longer weighted by the prefecture population. We obtain qualitatively similar results.

Alternative Identification Assumption: Column (2). We check the robustness of our main results under an alternative identification assumption. Column (2) reports the estimates from a Doubly-Robust Difference-in-Differences estimator. We first calculate a propensity score as the conditional probability of the YEOs via a logistic regression model and then generate Inverse Probability Treatment Weighting (IPTW) for the YEOs. We then run a DiD model with IPTW. The Doubly-Robust estimator is robust in the sense that the estimates are consistent as long as (i) the propensity score is correctly specified or (ii) the regression model is correctly specified (Bang and Robins, 2005). Since propensity score models assume selection on observables and DiD models assume selection on unobservables, Doubly-Robust DiD are robust to both selections on observables and unobservables. Our results are robust to this alternative identification assumption.

Post-Treatment Bias: Column (3). We include a host of time-dependent covariates, including police per 1,000 inhabitants and the log of overall crime rates. One potential concern is that the YEOs could potentially affect both crime and police resources either directly or indirectly, which may induce post-treatment bias (e.g., Rosenbaum, 1984; Montgomery et al., 2018). Column (3) reports the estimates from a DiD estimation that includes the interaction between baseline covariates measured at the baseline (i.e., prior to the enactment of the YEOs) and year fixed effects, adjusting for how baseline covariates differentially affect the outcome from year to year. Since all covariates are measured prior to the enactment of the YEOs, this specification alleviates potential concern about post-treatment bias. We exclude region specific time trends.

Goodman-Bacon Correction: Column (4). We exploit differential timing in the enactment of the YEOs across prefectures. Goodman-Bacon (2018) shows that treatment 
effects may be biased when units receive treatment at different times and treatment effects change over time. We apply the Goodman-Bacon correction method in Column (4). The results suggest that when evaluated at YCI = zero, the YEO's effect is qualitatively the same. However, when evaluated at YCI = mean, the YEO's effect is no longer statistically significant. We estimate the latter effect, using the grand-mean centered YCI.

Alternative Definitions of YCI: Columns (5) to (9). We use alternative definitions of YCI. To compute YCI, we need to compute the share $s_{p g}$ of yakuza syndicate $g$ in prefecture $p$. In the main text, we assume that the members of yakuza syndicate $g$ are distributed proportionally to the population in prefecture $p$ where yakuza syndicate $g$ operates. For notational convenience, let $Y C I^{p o p}$ denote the YCI that we have used so far.

First, we consider time-dependent YCI. So far we have treated that YCI as time-independent variables, in order to avoid post-treatment bias. To test whether our results are robust to this restriction, we modify regression model (1) as follows: add the (time-dependent) noninteraction term $Y C I_{p t}^{p o p}$ and replace time-independent $Y E O_{p t} \times Y C I_{p}^{p o p}$ with time-dependent $Y E O_{p t} \times Y C I_{p t}^{p o p}$. As shown in Column (5), our results are robust. The estimated coefficient of $Y C I_{p t}^{p o p}$ is negative and not statistically significant. This is likely because (i) YCI does not change much over time during this period and (ii) we control for region specific linear time trends, so that region specific linear time trends absorb much variation.

Now we recompute the share $s_{p g}$ based on alternative assumptions. First, suppose that the members of yakuza syndicate $g$ are distributed equally among all prefectures in which yakuza syndicate $g$ operates. Let $s_{p g}^{\text {naive }}$ denote the share that is calculated in this way, and let $Y C I_{p}^{\text {naive }}$ be the resulting YCI. Second, suppose that the members of yakuza syndicate $g$ are distributed proportionally to the population density of prefecture $p$ in which yakuza syndicate $g$ operates. Let $s_{p g}^{\text {density }}$ denote the share that is calculated in this way, and let $Y C I_{p}^{\text {density }}$ denote the resulting YCI. Using these two variants of YCI, we redo our estimation. As shown in Columns (6) and (7), our results are robust to the specifications.

Lastly, we use alternative indices for the regional competition among rival yakuza syndicates (instead of the YCI). First, we define the yakuza's presence based on the Ethnic Polarization index (Montalvo and Reynal-Querol, 2005) for Column (8). Second, we simply use the raw number of yakuza syndicates operating in each prefecture for YCI for Column (9). As shown in the two columns, our results are qualitatively similar and robust.

Amendment of Anti-Yakuza Laws: Column (10). The Anti-Yakuza Laws, which are nationwide laws, were amended in October 2012. Since our estimation strategy is based on the DiD approach which exploits the prefectural variation, the amendment of the nationwide 
laws should not affect our results, and this is why we did not take into account.

Here we examine this assumption. Let the treatment dummy $A Y L_{t}$ be equal to 1 before the amendment and to 0 after the amendment. We add, to regression model (1), a noninteraction term $A Y L_{t}$ and an interaction term $A Y L_{t} \times Y C I_{p}^{p o p}$. Either term is insignificant but the two elements of interest, $Y E O_{p t}$ and $Y E O_{p t} \times Y C I_{p}^{p o p}$, remain significant.

Tohoku Earthquake: Column (11). Japan experienced the Tohoku Earthquake on March 11, 2011. It is often said that yakuza members engaged in business in the affected areas after the earthquake. For example, some of them participated in the repair of nuclear reactors (Ramseyer, 2016) and in the restoration of the affected areas. These economic opportunities might affect yakuza activities. A simple way to eliminate potential effects of the earthquake is to exclude prefectures that were affected by this earthquake (i.e., Miyagi, Iwate, Fukushima, Ibaraki, Tochigi, Chiba, and Kanagawa) from our dataset. Even using this subsample, we still obtain qualitatively the same results.

Multiple Imputation and Monthly Level Data: Columns (12) and (13). Lastly, we examine the robustness of our estimation to potential errors in the outcome measurement in our data. First, the provided data on the yakuza is based on 37 out of 47 prefectures. To deal with missing data (10 prefectures and about $5 \%$ of the data is missing among the 37 prefectures), we conduct multiple imputations with 10 replications. The results using this variable are combined estimates from the 10 imputations, applying Rubin's rule (Rubin, 1987). Multiple implications rest on the missing-at-random assumption. To indirectly examine this, we conduct a diagnostic test that suggests whether the missingness of the yakuza data does not vary systematically across prefectures conditional on observable covariates included in our model. Therefore, the missing-at-random assumption is likely satisfied conditional on the observed covariates (Appendix C).

Second, the annual data on the number of yakuza members is linearly interpolated to the month level and missing data is dealt with multiple imputations. We run two robustness tests to potential concerns related to the measurement. In the first test, we use the linearly interpolated data but we do not impute the missing data; in the second test, we use the (nonimputed) annual data, instead of month-level interpolated data. We report the estimation results in Columns (12) and (13), and the results are robust to both alternative measures. 


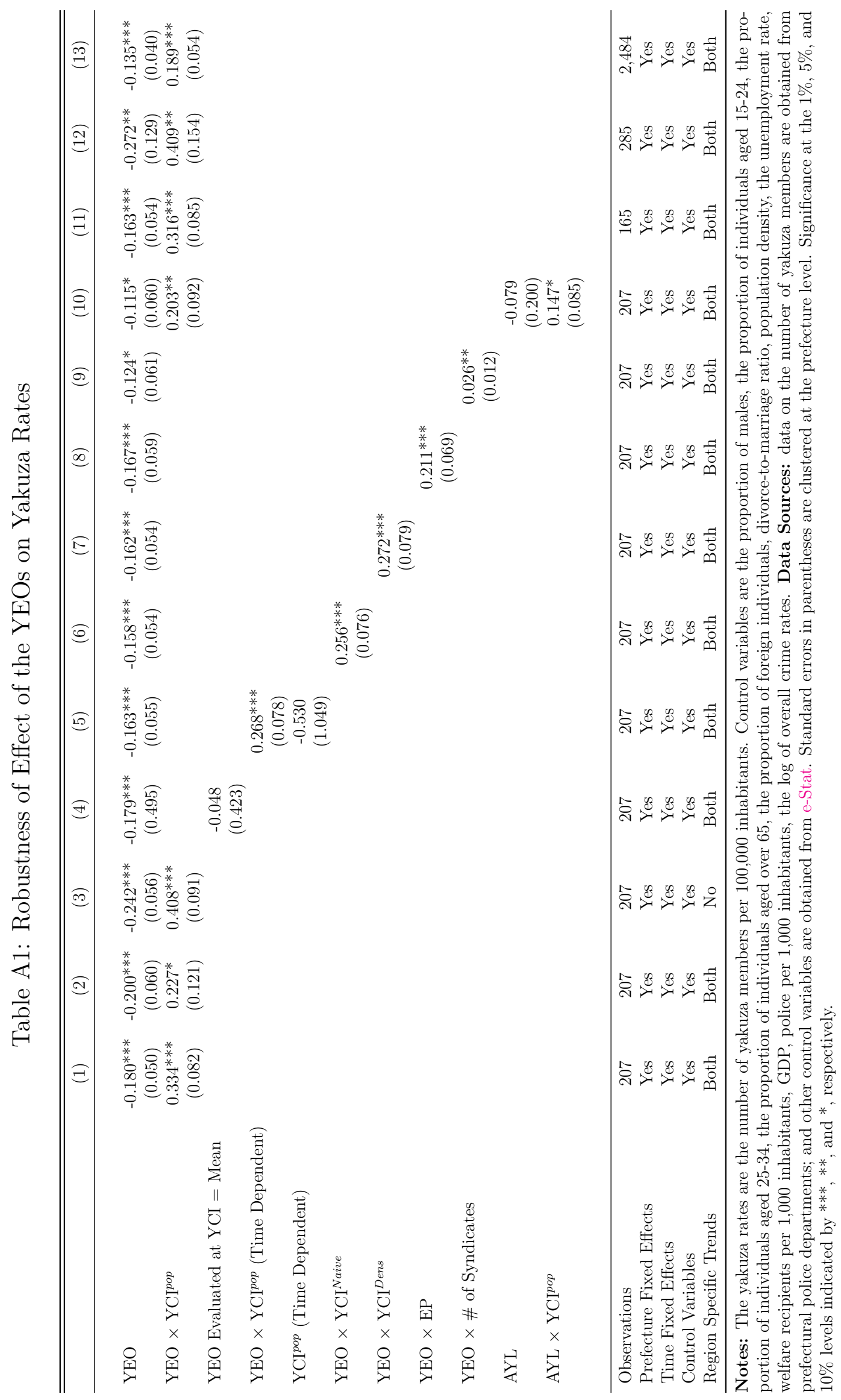




\section{B Designated Yakuza Syndicates}

Under the Anti-Yakuza Laws, twenty-one yakuza syndicates are "designated" during the period of the study. The criteria for the designation is that a yakuza syndicate has a hierarchical organizational structure, that its members use violence to earn money, and that its members have criminal records. Table A2 lists up all the designated yakuza syndicates. \#pref. of influence is the number of prefectures in which the particular yakuza syndicate operates. ${ }^{11}$

Table A2: Designated Yakuza Syndicates

\begin{tabular}{lr||lr}
\hline yakuza syndicate & \#pref. of influence & yakuza syndicate & \#pref. of influence \\
\hline Yamaguchi-gumi & 45 & Shinwa-kai & 1 \\
Inagawa-kai & 19 & Sōai-kai & 2 \\
Sumiyoshi-kai & 18 & Kyokudō-kai & 5 \\
Kudō-kai & 3 & Taishū-kai & 1 \\
Kyokuryu-kai & 1 & Sakaume-gumi & 1 \\
Aizukotetsu-kai & 2 & Kyokutō-kai & 15 \\
Kyōsei-kai & 1 & Azuma-gumi & 1 \\
Gōda-ikka & 3 & Matsuba-kai & 10 \\
Kozakura-ikka & 1 & Fukuhaku-kai & 4 \\
Asano-gumi & 2 & Namikawamutsumi-kai & 6 \\
Dōjin-kai & 4 & & \\
\hline
\end{tabular}

Data Sources: National Police Agency (2009)

\section{Missing-at-Random Assumption for Yakuza Data}

Our data on the number of yakuza members is based on 37 out of 47 prefectures. To deal with missing data, we use multiple imputations, which rests on the missing-at-random assumption. One potential concern is whether these 37 prefectures are selected randomly or not. We conduct a diagnostic test. We define a binary outcome: 1 if a prefecture reported the data; and 0 otherwise. We then run a diagnostic test by regressing this binary outcome on observed covariates. Table A3 reports the result: none of the coefficients is statistically significant. This suggests that reporting the data on the number of yakuza members is not

\footnotetext{
${ }^{11}$ There were twenty-two designated yakuza syndicates, but in 2011, two of them, both of which operated only in Okinawa, merged.
} 
systematically different across observed covariates, suggesting that the data is likely missing at random, conditional on observed covariates. Given this, we employ multiple imputations, where we impute missing values 10 times based on random draws from a distribution of possibilities (Rubin, 1987).

Table A3: Missing-at-Random Assumption for Yakuza Data

\begin{tabular}{lc}
\hline \hline Dependent Variable & Yakuza Data Reported \\
\hline & \\
YEO & 0.048 \\
& $(0.119)$ \\
YEO $\times$ YCI & 0.114 \\
& $(0.195)$ \\
Proportion of Males & 4.524 \\
& $(13.265)$ \\
Proportion of Aged 15-24 & 10.515 \\
& $(13.466)$ \\
Proportion of Aged 25-34 & 5.189 \\
Proportion of Aged 65+ & $(14.286)$ \\
Proportion of Foreign People & 4.067 \\
Unemployment Rates & $(6.776)$ \\
Welfare Recipients per 1,000 Inhabitants & 7.262 \\
GDP & $(16.620)$ \\
Population Density & 0.148 \\
& $(0.119)$ \\
& 0.004 \\
& $(0.014)$ \\
& 0.004 \\
& $(0.009)$ \\
& -0.000 \\
& $(0.000)$ \\
& -0.182 \\
& $(0.266)$ \\
& -0.107 \\
& $(0.124)$ \\
& \\
& \\
& \\
&
\end{tabular}

Notes: Yakuza data reported indicates whether a prefecture reported data on yakuza membership. Control variables: see Table 2. Data Sources: see Table 2. Significance at the 1\%, 5\%, and $10 \%$ levels indicated by ***, **, and ${ }^{*}$, respectively. 


\section{Summary Statistics of Outcome and Control Vari- ables}

Table A4: Summary Statistics of Outcome and Control Variables

\begin{tabular}{lrr}
\hline \hline & Mean & Std. Dev. \\
\hline Outcome Variables: & & \\
Yakuza Rates & 45.725 & 20.399 \\
& & \\
Control Variables: & & \\
Proportion of Males & 0.482 & 0.010 \\
Proportion Aged 15-24 & 0.096 & 0.008 \\
Proportion Aged 25-34 & 0.112 & 0.012 \\
Proportion Aged 65+ & 0.251 & 0.028 \\
Proportion of Foreign People & 0.012 & 0.007 \\
Population Density & 653.677 & 1159.631 \\
Unemployment Rate & 4.271 & 0.796 \\
Welfare Recipients per 1,000 Inhabitants & 12.934 & 6.814 \\
GDP (trillion) & 11.253 & 15.594 \\
Police per 1,000 Inhabitants & 1.859 & 0.307 \\
Overall Crime Rates & 10.366 & 5.0444 \\
\hline
\end{tabular}

Notes: The yakuza rates are the numbers of yakuza members per 100,000 inhabitants. Data Sources: data on the number of yakuza members are obtained from prefectural police departments; data on overall crime rates (overall violent crime and overall property crime) are obtained from the NPA; other control variables are obtained from e-Stat. 